\title{
Lack of insurance coverage for testing supplies is associated with poorer glycemic control in patients with type 2 diabetes
}

\author{
Samantha L. Bowker, Chad G. Mitchell, Sumit R. Majumdar, Ellen L. Toth, Jeffrey A. Johnson
}

ß See related article page 48

\section{Abstract}

Background: Public insurance for testing supplies for selfmonitoring of blood glucose is highly variable across Canada. We sought to determine if insured patients were more likely than uninsured patients to use self-monitoring and whether they had better glycemic control.

Methods: We used baseline survey and laboratory data from patients enrolled in a randomized controlled trial examining the effect of paying for testing supplies on glycemic control. We recruited patients through community pharmacies in Alberta and Saskatchewan from Nov. 2001 to June 2003. To avoid concerns regarding differences in provincial coverage of selfmonitoring and medications, we report the analysis of Alberta patients only.

Results: Among our sample of 405 patients, $41 \%$ had private or public insurance coverage for self-monitoring testing supplies. Patients with insurance had significantly lower hemoglobin $A_{1 c}$ concentrations than those without insurance coverage $(7.1 \%$ v. $7.4 \%, p=0.03)$. Patients with insurance were younger, had a higher income, were less likely to have a high school education and were less likely to be married or living with a partner. In multivariate analyses that controlled for these and other potential confounders, lack of insurance coverage for selfmonitoring testing supplies was still significantly associated with higher hemoglobin $\mathrm{A}_{1 \mathrm{c}}$ concentrations (adjusted difference $0.5 \%, p=0.006$ )

Interpretation: Patients without insurance for self-monitoring test strips had poorer glycemic control.

CMAJ 2004;171(1):39-43

7 he treatment of patients with diabetes aims to establish optimum metabolic control while controlling for comorbidities such as hypertension and dyslipidemias. ${ }^{1}$ Strategies aimed at achieving tighter glycemic control are known to reduce microvascular complications in type 2 diabetes. $^{2}$

Self-care activities play an important role in the achievement of optimal metabolic control. Self-monitoring of blood glucose (hereafter referred to as self-monitoring) is considered a cornerstone of this self-care, ${ }^{1,3}$ although the precise role and benefits of self-monitoring are not entirely clear. ${ }^{4-7}$ Insufficient evidence of the role of self-monitoring in type 2 diabetes leaves us with vague recommendations in current clinical practice guidelines. ${ }^{1,3}$ In a cross-sectional study from a large US managed-care organization, Karter and colleagues concluded that more frequent selfmonitoring testing was associated with better glycemic control. ${ }^{8}$ In a small Canadian study, Nyomba and colleagues showed that supplying free strips increased compliance with self-monitoring and enhanced diabetes selfmanagement, which was associated with lower hemoglobin $A_{1 c}$ concentrations compared with patients who did not receive free strips. ${ }^{9}$

The cost of self-monitoring is not inconsequential, to our health care system as a whole or to individual patients. ${ }^{910}$ Each self-monitoring testing strip costs approximately $\$ 1$, which, with more frequent testing to achieve optimal glycemic control, could lead to substantial costs for health care systems and individual users. Insurance coverage for diabetes testing supplies varies widely across provinces and territories in Canada. ${ }^{10,11}$ In this study, our aim was to investigate the relation between insurance coverage for diabetes testing supplies and glycemic control in patients with type 2 diabetes. We hypothesized that even in a publicly funded health care system, lack of insurance coverage specifically for self-monitoring supplies would be associated with lesser degrees of glycemic control.

\section{Methods}

Currently we are conducting a randomized controlled trial to examine the effect of providing access to self-monitoring supplies on the control of diabetes. This study was approved by the Health Research Ethics Board of the University of Alberta and the Capital Health Authority in Edmonton and by the Regina Health District Research Ethics Board. For this trial, we recruited patients through a network of community pharmacies in Alberta (Edmonton and Calgary) and Saskatchewan (Regina) from Nov. 1, 2001 through June 30, 2003. To be included in the study, patients must have had type 2 diabetes of at least 1-year duration, be 30 years of age or older and not on insulin. Patients that controlled their diabetes by diet alone were included in the study if they met the above criteria. We excluded pregnant patients and those with ges- 
tational diabetes. Patients taking insulin were excluded from the study because the use of self-monitoring by such patients is considered essential by the Canadian Diabetes Association. ${ }^{1}$ In this article we report on an initial examination of the eligible patients and the relation between self-reported insurance coverage and glycemic control.

We asked patients to complete a survey and mail it to the research office. We also provided patients with lab requisitions for hemoglobin $\mathrm{A}_{1 \mathrm{c}}$ concentrations, which were analyzed in central laboratories in Calgary and Edmonton. The survey contained demographic and self-reported clinical information regarding duration of diabetes, comorbidities and complications attributed to diabetes, and diabetes education experience. Patients' insurance status was assessed by study pharmacists at the time of the initial assessment. We asked patients if they had any type of insurance coverage, either private or public, that covered self-monitoring testing strips. The levels or forms of insurance coverage for diabetes test strips, such as reimbursement, copayments or deductibles, were not otherwise recorded.

We included in the survey the Summary of Diabetes Self-Care Activities (SDSCA), a validated measure of self-efficacy with diabetes self-care behaviours. ${ }^{12}$ The 11 questions in the SDSCA assess 6 dimensions of the diabetes self-care regimen: general diet, specific diet, exercise, self-monitoring of blood glucose, foot care and smoking. Respondents report the number of days per week that they perform each self-care activity. Performance of recommended frequency of self-monitoring was assessed using the 2 self-monitoring questions in the SDSCA (see online Appendix 1 at www.cmaj.ca/cgi/content/full/171/1/39/DC1). The average of these 2 items represents the SDSCA self-monitoring of blood glucose score; a difference of 1.0 on this scale represents, on average, a patient who tests more frequently by at least 1 day a week.

Perceived barriers to self-monitoring were assessed with 1 subscale of the Environmental Barriers to Adherence Scale (EBAS). ${ }^{13}$ The EBAS measures a total of 60 barriers across 4 areas of selfcare behaviour (diet, exercise, blood glucose testing and medica- tion). The EBAS self-monitoring blood glucose testing subscale consists of 13 questions assessing barriers to self-monitoring, including financial access (see online Appendix 1 [URL above]). ${ }^{13}$ The EBAS does not have an explicit criterion for important differences; as a relative scale, it can be interpreted that higher scores indicate more barriers.

We initially compared the subgroups of respondents with and without insurance coverage for diabetes testing supplies in terms of sociodemographic variables and hemoglobin $\mathrm{A}_{1 \mathrm{c}}$ concentrations, using independent sample $t$ tests and $\chi^{2}$ tests of association, as appropriate.

We subsequently examined the relation between insurance coverage for self-monitoring supplies and glycemic control (i.e., hemoglobin $\mathrm{A}_{1 \mathrm{c}}$ concentrations) using multiple linear regression, to control for sociodemographic variables and the frequency of and barriers to self-monitoring. We excluded from the multivariate model the overall number of physician visits, as this was the same between those with and those without insurance and was highly correlated with the number of diabetes-related physician visits. We tested the hypothesis that there is no difference in the relation between hemoglobin $\mathrm{A}_{\mathrm{lc}}$ concentrations and those with and those without insurance that covers self-monitoring test strips. We considered interaction terms between having insurance and the self-reported outcome and sociodemographic variables; we found no significant $(p<0.10)$ interaction terms and therefore report only the results of the main effects model. All hypotheses were assessed using 2-sided tests of significance at the conventional level of $\alpha=0.05$.

\section{Results}

A total of 433 patients were recruited into the study and had hemoglobin $\mathrm{A}_{\mathrm{lc}}$ measurements available for this analysis. Of these patients, 405 (93.5\%) were from Alberta. To

Table 1: Demographic variables for subjects with and without insurance that covers self-monitoring blood glucose testing strips

\begin{tabular}{|c|c|c|c|}
\hline Variable & $\begin{array}{l}\text { With insurance } \\
\qquad n=166\end{array}$ & $\begin{array}{l}\text { Without insurance } \\
\qquad n=239\end{array}$ & $p$ value \\
\hline Age, mean (SD), yr & $59.2(10.8)$ & $68.2(10.7)$ & $<0.001$ \\
\hline Male, \% & 44.3 & 55.7 & 0.172 \\
\hline$\%$ with income $\geq \$ 40000$ & 58.2 & 41.8 & $<0.001$ \\
\hline$\%$ with high school education & 47.4 & 52.6 & 0.001 \\
\hline Duration of diabetes, mean (SD), yr & $7.3(6.6)$ & $8.3(7.3)$ & 0.160 \\
\hline$\%$ taking oral agents for diabetes mellitus & 39.9 & 60.1 & 0.182 \\
\hline$\%$ married or living with partner & 48.1 & 51.9 & $<0.001$ \\
\hline $\begin{array}{l}\text { Years since last visit to diabetes } \\
\text { educational clinic, mean (SD) }\end{array}$ & $3.1(2.8)$ & $4.2(5.0)$ & 0.019 \\
\hline $\begin{array}{l}\text { Visits to the doctor in the last } 6 \mathrm{mo} \text {, } \\
\text { mean (SD) }\end{array}$ & $5.0(4.3)$ & $4.5(3.6)$ & 0.182 \\
\hline $\begin{array}{l}\text { Visits to the doctor for diabetes in the last } \\
6 \text { mo, mean (SD) }\end{array}$ & $2.8(3.8)$ & $2.4(2.5)$ & 0.186 \\
\hline SDSCA $_{\mathrm{SMBG}}(\text { range: } 0-7)^{*}$ & $4.1(2.4)$ & $3.3(2.4)$ & 0.002 \\
\hline $\mathrm{EBAS}_{\mathrm{SMBG}}$ (range: $\left.0-100\right) \dagger$ & $21.7(8.1)$ & $20.6(8.7)$ & 0.227 \\
\hline
\end{tabular}

Note: $\mathrm{SD}=$ standard deviation, $\mathrm{SDSCA}=$ Summary of Diabetes Self-Care Activities, EBAS = Environmental Barriers to Adherence Scale, SMBG = Self-Monitoring of Blood Glucose.

*Higher scores on the SDSCA ${ }^{12}$ measure mean more frequent self-monitoring of blood glucose; a difference of 1

indicates, on average, someone who tests at least 1 day per week more frequently.

†Higher scores on the EBAS ${ }^{13}$ indicate greater perceived barriers to self-monitoring of blood glucose. 
avoid concerns regarding differences in provincial coverage of self-monitoring and medications, we present the remainder of our results only for this group of patients. Less than half of the respondents ( $41 \%$ ) reported having some form of private or public insurance coverage for self-monitoring testing supplies. Patients with this type of insurance were significantly younger compared with those without insurance (mean age 59.2 years v. 68.2 years; $p<0.001$ ) (Table 1). Patients with insurance had significantly higher incomes (58.2\% of patients with insurance v. $41.8 \%$ of patients without insurance had a household income $\geq \$ 40000$, $p<0.001$ ). A smaller proportion of patients with insurance had a high school education compared with patients without insurance $(47.4 \%$ v. $52.6 \%, p=0.001)$. Patients with insurance were less likely than those without insurance to be married or living with a partner $(48.1 \%$ v. $51.9 \%$, $p<0.001)$. There were no significant differences between patients with and without insurance for duration of diabetes, oral agents for diabetes mellitus, sex or the number of times a patient had seen the doctor in the last 6 months. Other patient characteristics and selected survey responses, stratified by insurance status, are presented in Table 1.

Overall, subjects with insurance that covered selfmonitoring testing strips had significantly lower hemoglobin $\mathrm{A}_{1 \mathrm{c}}$ concentrations compared with those without insurance $(7.1 \%$ v. $7.4 \%, p=0.03)$ (Table 2$)$. When hemoglobin $\mathrm{A}_{\mathrm{lc}}$ concentrations were stratified by levels of glucose control according to the Canadian Diabetes Association's Clinical Practice Guidelines, ${ }^{1}$ the largest difference between patients with and without insurance occurred in the group with the poorest glycemic control (hemoglobin $\mathrm{A}_{1 \mathrm{c}}$ concentrations > 8.4\%) (Fig. 1).

After controlling for statistically significant and clinically important covariates in the multiple regression models, we found that patients with insurance for testing strips had significantly lower hemoglobin $\mathrm{A}_{1 \mathrm{c}}$ concentrations than patients without insurance. On average, patients with insurance for strips had hemoglobin $\mathrm{A}_{1 \mathrm{c}}$ values $0.5 \%$ lower than patients without insurance (Table 3). In these multivariate models, poorer glycemic control was associated with longer duration of diabetes and greater self-reported environmental barriers to self-monitoring (Table 3).

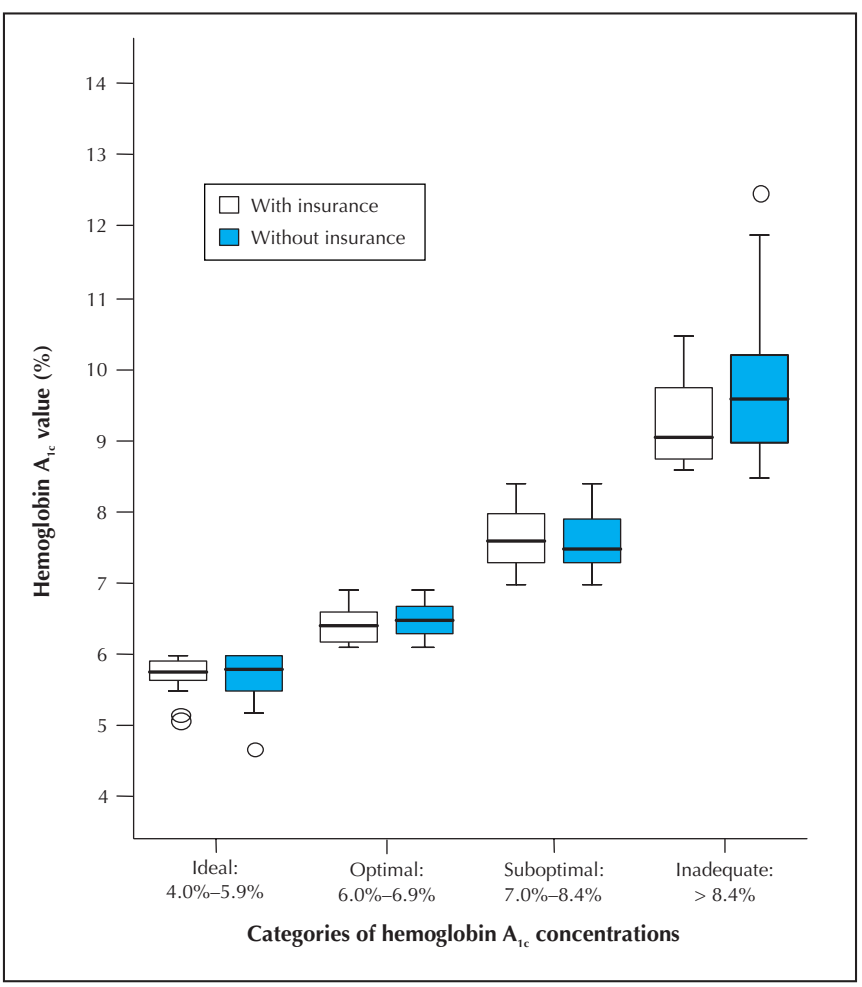

Fig. 1: Glycemic control ${ }^{1}$ for type 2 diabetes mellitus patients with and without insurance that covers self-monitoring blood glucose testing strips. The midline of each box marks the median. The bottom and top of each box represent the 25th and 75th percentiles; therefore, the height of the box is the interquartile range (IQR). Lines projecting from the top and bottom of each box indicate the most extreme values that were not more than 1.5 IQRs beyond the box. Values that lie more than 1.5 IQRs beyond the top or bottom of the box (outliers) are shown individually.

\begin{tabular}{|c|c|c|c|}
\hline \multirow{2}{*}{$\begin{array}{l}\text { Adequacy of glycemic } \\
\text { control }^{1}\left(\mathrm{HbA}_{1 \mathrm{c}}\right. \\
\text { concentration, \%) }\end{array}$} & \multicolumn{2}{|c|}{ Mean $\mathrm{HbA}_{1 \mathrm{c}}$ concentration, \% (SD) } & \multirow[b]{2}{*}{$\begin{array}{c}\text { Difference, } \% \\
\quad(p \text { value })\end{array}$} \\
\hline & $\begin{array}{l}\text { Subjects with } \\
\text { insurance }\end{array}$ & $\begin{array}{l}\text { Subjects without } \\
\text { insurance }\end{array}$ & \\
\hline Ideal (4.0-5.9) & $\begin{array}{c}5.7(0.3) \\
n=28\end{array}$ & $\begin{array}{c}5.7(0.3) \\
n=31\end{array}$ & $\begin{array}{c}0.00 \\
(0.968)\end{array}$ \\
\hline Optimal (6.0-6.9) & $\begin{array}{c}6.4(0.2) \\
n=55\end{array}$ & $\begin{array}{c}6.5(0.2) \\
n=76\end{array}$ & $\begin{array}{c}0.04 \\
(0.316)\end{array}$ \\
\hline Suboptimal (7.0-8.4) & $\begin{array}{c}7.6(0.4) \\
n=67\end{array}$ & $\begin{array}{c}7.6(0.4) \\
n=91\end{array}$ & $\begin{array}{c}0.05 \\
(0.443)\end{array}$ \\
\hline Inadequate (> 8.4) & $\begin{array}{c}9.4(1.1) \\
n=16\end{array}$ & $\begin{array}{c}9.8(1.2) \\
n=41\end{array}$ & $\begin{array}{c}0.4 \\
(0.252)\end{array}$ \\
\hline All levels & $\begin{array}{c}7.1(1.2) \\
n=166\end{array}$ & $\begin{array}{l}7.4(1.4) \\
n=239\end{array}$ & $\begin{array}{c}0.3 \\
(0.030)\end{array}$ \\
\hline
\end{tabular}

Note: $\mathrm{HbA}_{\mathrm{lc}}=$ hemoglobin $\mathrm{A}_{\mathrm{lc}} \mathrm{SD}=$ standard deviation 


\section{Interpretation}

In this cross-sectional study, we observed that patients without insurance for self-monitoring supplies had significantly worse glycemic control. The difference of $0.5 \%$ in hemoglobin $\mathrm{A}_{\mathrm{ic}}$ concentrations is considered clinically significant, representing approximately half of the effect observed in the UK Prospective Diabetes Study Group with intensive glycemic control. ${ }^{2}$ The disparity between the 2 groups was primarily evident in patients with the worst blood glucose control (hemoglobin $\mathrm{A}_{1 \mathrm{c}}$ concentrations $>8.4 \%$ ). That this difference was observed in this upper, unbounded category may not be a surprise, but it serves as a reminder that patients in the most dire situations might benefit the most from clinical intervention.

As might be expected, barriers to self-care activities, as measured by the EBAS, were also associated with poorer glycemic control. As we were most interested in the financial barriers to testing, we further explored the response to the "cost as a barrier to self-monitoring" item in the EBAS and found that those with insurance more frequently indicated that cost was never, or rarely, a barrier to selfmonitoring compared with those without insurance.

These findings support our original hypotheses and are consistent with the conclusions of Karter and colleagues, who observed that self-monitoring practice patterns may be sensitive to out-of-pocket expenditures for self-monitoring testing strips, especially for those with lower incomes enrolled in a large managed-care organization. ${ }^{8}$ Likewise, $\mathrm{Ny}-$ omba and colleagues showed that patients who were given free self-monitoring test strips had lower hemoglobin $A_{1 c}$

Table 3: Multivariate regression results: insurance coverage and glycemic control*

\begin{tabular}{|c|c|c|}
\hline Dependent variable: hemoglobin $A_{1 c}$ & Coefficient (SE) & $p$ value \\
\hline Constant & $6.43(0.95)$ & $<0.001$ \\
\hline Age, yr & $-0.01(0.01)$ & 0.279 \\
\hline Sex $(1=$ male, $0=$ female $)$ & $0.15(0.16)$ & 0.360 \\
\hline $\begin{array}{l}\text { Income }(1=<\$ 40000 \\
0=\geq \$ 40000)\end{array}$ & $-0.24(0.19)$ & 0.199 \\
\hline $\begin{array}{l}\text { High school education } \\
(1=\text { yes, } 0=\text { no) }\end{array}$ & $-0.17(0.17)$ & 0.324 \\
\hline Duration of diabetes mellitus, yr & $0.04(0.01)$ & 0.002 \\
\hline $\begin{array}{l}\text { Insurance for testing strips } \\
(1=\text { yes, } 0=\text { no })\end{array}$ & $-0.47(0.17)$ & 0.006 \\
\hline $\begin{array}{l}\text { Oral agents for diabetes mellitus } \\
(1=\text { yes, } 0=\text { no })\end{array}$ & $0.61(0.37)$ & 0.102 \\
\hline $\begin{array}{l}\text { Married or living with partner } \\
(1=\text { yes, } 0=\text { no })\end{array}$ & $-0.00(0.17)$ & 0.993 \\
\hline $\begin{array}{l}\text { No. of times you have seen the doctor } \\
\text { for diabetes in the last } 6 \text { mo }\end{array}$ & $0.03(0.02)$ & 0.164 \\
\hline $\mathrm{EBAS}_{S M B G}$ & $0.03(0.01)$ & $<0.001$ \\
\hline SDSCA $_{\mathrm{SMBG}}$ & $-0.05(0.03)$ & 0.149 \\
\hline
\end{tabular}

Note: $\mathrm{SE}=$ standard error, $\mathrm{SDSCA}=$ Summary of Diabetes Self-Care Activities, EBAS $=$ Environmental Barriers to Adherence Scale, SMBG = Self-Monitoring of Blood Glucose.

*Sample size is reduced $(n=290)$ owing to listwise deletion of cases with missing data on covariates. concentrations and average blood glucose and insulin doses compared with control subjects who did not receive free test strips. ${ }^{9}$ The validity of this second study, however, is difficult to gauge and is weakened by the small sample size $(n=62)$ and the large losses during follow-up (44\%).

The main limitation of our study is the cross-sectional and correlational design, which limits the ability to draw inferences of causality. A randomized trial of free selfmonitoring supplies (as opposed to "usual health care policy"), such as we are conducting, is required to address this limitation. We relied only on self-report for the type of insurance coverage and did not have data regarding copayments or deductibles. Nonetheless, our use of a dichotomous variable (insurance present or absent) would tend to minimize rather than exaggerate differences between grades of insurance. Further, the sample from which we obtained data may not be generalizable to all patients with type 2 diabetes in other regions or provinces and under different public insurance schemes for diabetes testing supplies. However, the sample was drawn from patients seen in community pharmacies willing to enrol in a study and, from a clinical and demographic perspective, we feel the sample was typical for people with type 2 diabetes.

Increasingly, providers, payers, policy-makers and purchasers of care recognize diabetes as one of the most prevalent and expensive health care problems. ${ }^{14}$ Accessibility and costs of self-monitoring testing supplies remain serious areas of concern for provincial and territorial governments in Canada. ${ }^{15}$ We previously estimated that the mean total cost for diabetes testing supplies per beneficiary with dispensation claims for testing supplies in 1996 was \$241 in Saskatchewan. ${ }^{10}$ Even with public insurance, financial barriers to self-monitoring may still exist; less than half of the people we identified with diabetes had dispensations for diabetes test strips. ${ }^{10}$ About $74 \%$ of people taking insulin had dispensations for diabetes testing strips; among patients taking oral hypoglycemic agents alone, only $50 \%$ had dispensations for testing strips.

If patients with insurance coverage for self-monitoring supplies can achieve better glycemic control (i.e., lower hemoglobin $A_{1 c}$ concentrations), it would be beneficial to invest in relatively low cost preventive items such as testing strips. In this current analysis, patients without insurance for self-monitoring test strips reported greater financial barriers to self-monitoring and had poorer glycemic control. For some patients, reduced financial barriers to self-monitoring supplies may facilitate self-management of their disease, with the results of monitoring providing valuable information on efficacy of their diabetes self-care activities.

This article has been peer reviewed.

From the Institute of Health Economics (Bowker, Majumdar, Toth, Johnson), Pharmaceutical Policy and Programs, Alberta Health and Wellness (Mitchell), the University of Alberta, Department of Medicine (Majumdar, Toth) and the Department of Public Health Sciences (Johnson), Edmonton, Alta.

Competing interests: None declared. 
Contributors: Samantha Bowker conducted the statistical analysis and prepared and revised the manuscript. Chad Mitchell contributed to the statistical analysis and reviewed the manuscript. Sumit Majumdar and Ellen Toth are coinvestigators who participated in the design of the full study and reviewed early drafts of the manuscript. Jeffrey A. Johnson is the principal investigator and responsible for all aspects of the study, including the collection and analysis of data and revisions to the manuscript. All authors approved the final version of the manuscript.

Acknowledgements: This project was supported by grants from the Institute of Health Economics, the Canadian Diabetes Association and Aventis Pharma Canada.

The research is also supported by a New Emerging Team (NET) grant to the Alliance for Canadian Health Outcomes Research in Diabetes (ACHORD). The ACHORD NET grant is sponsored by the Canadian Diabetes Association, the Heart and Stroke Foundation of Canada, the Kidney Foundation of Canada, along with the Canadian Institutes for Health Research's Institute of Nutrition, Metabolism and Diabetes and Institute of Circulatory and Respiratory Health.

Sumit Majumdar and Jeffrey Johnson are Population Health Investigators at the Alberta Heritage Foundation for Medical Research, Sumit Majumdar is a New Investigator for the Canadian Institutes of Health Research and Jeffrey Johnson holds a Canada Research Chair in Diabetes Health Outcomes.

\section{References}

1. Canadian Diabetes Association Clinical Practice Guidelines Expert Committee. Canadian Diabetes Association 2003 Clinical Practice Guidelines for the Prevention and Management of Diabetes in Canada. Can 7 Diabetes 2003;27 (Suppl 2):S1-3.

2. UK Prospective Diabetes Study Group. Intensive blood-glucose control with sulphonylureas or insulin compared with conventional treatment and risk of complications in patients with type 2 diabetes (UKPDS 33). Lancet 1998;352. 837-53.

3. Goldstein DE, Little RR, Lorenz RA, Malone JI, Nathan DM, Peterson CM; American Diabetes Association. Tests of glycemia in diabetes. Diabetes Care 2004;27(Suppl 1):S91-3.

4. Fontbonne A, Billault B, Acosta M, Percheron C, Varenne P, Besse A, et al. Is glucose self-monitoring beneficial in non-insulin-treated patients? Results of a randomized comparative trial. Diabetes Metab 1989;15:255-60.

5. Franciosi M, Pellegrini F, De Berardis G, Belfiglio M, Cavaliere D, Di Nardo $\mathrm{B}$, et al. The impact of blood glucose self-monitoring of metabolic control and quality of life in type 2 diabetic patients. Diabetes Care 2001;24:1870-7.

6. Harris MI. Frequency of blood glucose monitoring in relation to glycemic control in patients with type 2 diabetes. Diabetes Care 2001;24:979-82.

7. Coster S, Gullifod MC, Seed PT, Powrie JK, Swaminathan R. Monitoring blood glucose control in diabetes mellitus: a systematic review. Health Technol Assess 2000;4(12):i-iv, 1-93.

8. Karter AJ, Ferrara A, Darbinian JA, Ackerson LM, Selby JV. Self-monitoring of blood glucose: language and financial barriers in a managed care population with diabetes. Diabetes Care 2000;23:477-83.

9. Nyomba BLG, Berard L, Murphy LJ. The cost of self-monitoring of blood glucose is an important factor limiting glycemic control in diabetic patients. Diabetes Care 2002;25:1244-5.

10. Mitchell CG, Simpson SH, Johnson JA. Observed costs of diabetes testing supplies in Saskatchewan. Can 7 Clin Pharmacol 2002;9:41-2.

11. Canadian Diabetes Association. The prevalence and costs of diabetes. Canadian Diabetes Association in partnership with Association Diabete Quebec. 2000. Available: www.diabetes.ca/files/PrevalenceandCost.pdf (accessed 2004 Apr 05).

12. Toobert DJ, Hampton SE, Glasgow RE. The Summary of Diabetes SelfCare Activities measure: results from 7 studies and a revised scale. Diabetes Care 2000;23:943-50.
13. Irvine AA, Saunders JT, Blank MB, Carter WR. Validation of scale measuring environmental barriers to diabetes-regimen adherence. Diabetes Care 1990;13:705-11.

14. Dawson KG, Gomes D, Gerstein H, Blanchard JF, Kahler KH. The economic cost of diabetes in Canada, 1998. Diabetes Care 2002;25:1303-7.

15. Canadian Diabetes Association. Diabetes report card 2001: provincial, territorial and federal policy and programs for people with diabetes. Canadian Diabetes Association in partnership with Association Diabete Quebec. 2001. Available: www.diabetes.ca/Files/cda_report_card.pdf (accessed 2004 May 10).

Correspondence to: Dr. Jeffrey A. Johnson, Institute of Health Economics, 1200-10405 Jasper Ave., Edmonton AB T5J 3N4; jeff.johnson@ualberta.ca

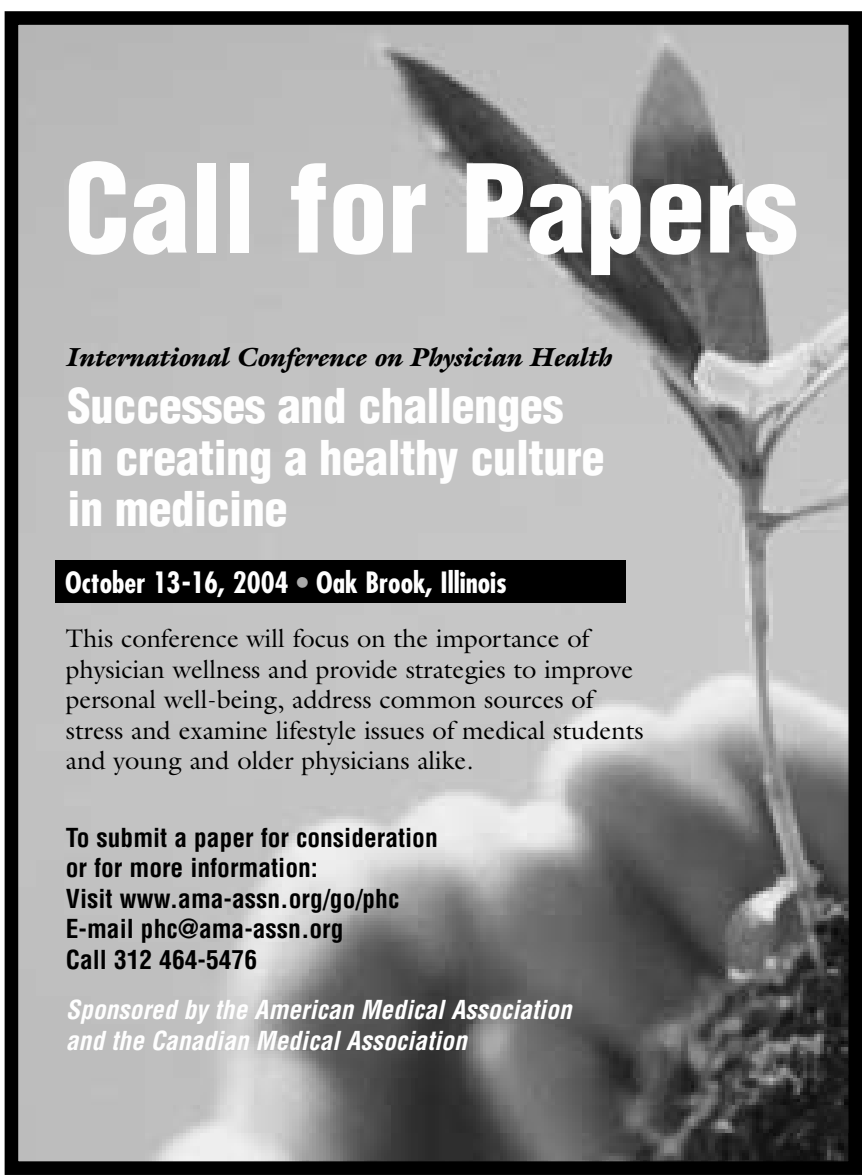

